\title{
An Analysis Report of College English Classroom Teaching in the Grading Model
}

\author{
Liu Peng \\ School of Foreign Languages, Sichuan University of Science and Engineering, Zigong, China \\ Chunrong $\mathrm{Wu}$ \\ School of Foreign Languages, Sichuan University of Science and Engineering, Zigong, China
}

Xianjun Tan

International Cooperation and Exchanges Office, Sichuan University of Science and Engineering, Zigong, China

\begin{abstract}
Based on data collected from Grade 2015 and Grade 2016, the present article mainly analyzes current situations of the grading model being implemented in a west provincial university. As frontline teachers, we cannot participate in the decision of which model to use, but can try our best to conduct frequent reflection and make necessary changes in classroom teaching for the good of college students' achievements in English course. Due mostly to the limitations of one teacher's first-hand experience, the research seems hard to hold water, and more are expected to participate in this topic. Only by means of active exploration and generous contributions from all teachers and educators concerned, will China College English be improved and productive in developing all-around talents needed for the realization of Chinese dreams.
\end{abstract}

Index Terms - grading model, college English, classroom teaching, CET-4

\section{INTRODUCTION}

In recent years, more exactly since 1999, with an increased enrollment in universities and colleges throughout China, students present a wider diversity of levels in English proficiency, not only between key universities and common ones, equal level of universities in different provinces or cities, but also within one college or school, or even one major of classes in the same university. As far as I know, quite a number of universities and colleges are still very much dependent of the unitary textbooks though the grading model is underway for non-English major undergraduates. Even for some responsible teachers who adopt flexible methods in classroom teaching, it is far from satisfaction for various levels of learners' English language.

In 2007 in the latest version of College English Curriculum Requirements, State Education Commission proposes that China College English course "should ensure that students at different levels receive adequate training and make improvement in their ability to use English", because not only does the English course provide basic knowledge, but it also is a capacity enhancement course helping students to widen students' horizons and learn about diverse cultures in the world. This point is emphasized in the strategy of "one belt, one road" initiated by President Xi, China should pose a gesture of openness, inclusiveness and diversity to the world. Furthermore, the English language "not only serves as an instrument, but also has humanistic values".

Our university belongs to second-batch universities (common provincial undergraduates universities) with students from 23 provinces and cities in China. The first characteristic determines students' overall lower level of English because in a university characterized by science and engineering higher percentage of students are not ideal in arts subjects like English. And the second point decides students' sharp contrast in individuals' levels of the English language because every province (or some cities) has a slightly different testing system in College Entrance Examination. As a consequence, the thinner the grading standards are, the more efficient the classroom teaching will be, and the better it will do to students' future development in the second language acquisition.

\section{REVIEW}

In my previous article entitled "The Exploring Practice of Grading Model in College English Teaching”, I illustrate three points of drawbacks and limitations presented in the grading model. Besides that the testing before grading is not quite scientific and this model is more exam-oriented as well, the grading teaching can strike students' confidence more than encouragement because current grading method is very rough and even going far from the initial intention of the reformation, failing to take students' learning interests, study motivation and especially their majors and preferences of their future career into consideration.

A. Initial Exploration in Grade 2015 
In first semester of Grade 2015, college freshmen are ranked as level A and level B on basis of their scores of a objectively-graded test with a total score of 70 point. In table 1 below, we can see how students are distributed differently. Due to almost close standard (one point or so) of students' results in the grading test, larger numbers of classes are set up for students belonging to science or engineering majors because mostly those students are science students in senior high school, such as College of Science and science students are normally stereotyped as "not good" at language learning. To the contrary, greater numbers of students are in level A classes on account of more arts students' enrollment like School of Economics and Management, and arts students are believed to be smarter at language learning. In addition to that, the advantages of English learning are vividly shown in Item 2 of Table 1, which emphasizes how important solid foundation is, and perfect if coached intensely. Both in the first and second semesters, liberal arts schools such as schools of Economics and Management, Humanities, Politics and Law stay advantageous higher ratio than the average percentage besides an exception in College of Material and Chemical Engineering in the first semester and College of Science in the second semester, which are well worth the applause.

TABLE 1:

CLASS DISTRIBUTIONS OF GRADE 2015

\begin{tabular}{|c|c|c|c|c|}
\hline \multirow{2}{*}{ Colleges \&.Schools } & \multicolumn{2}{|c|}{ Item 1} & \multicolumn{2}{|l|}{ Item 2} \\
\hline & $\mathbf{A}$ & $\mathbf{B}$ & $1^{\text {st }}$ Semester & $2^{\text {nd }}$ Semester \\
\hline Materials and Chemical Engineering & 6 & 7 & 63 (4 no show) & $20.56 \%$ (4 no show) \\
\hline Chemical and Pharmaceutical Engineering & 3 & 2 & 58.21 (3 no show) & $21.05 \%(2$ no show $)$ \\
\hline Mechanical Engineering & 5 & 5 & 54.29 (2 no show) & $22.64 \%$ (2 no show) \\
\hline Computer Science & 4 & 5 & 59.7 (1 no show) & $22.22 \%$ (5 no show) \\
\hline Architecture Engineering & 3 & 3 & 56.57 (2 no show) & $24.39 \%(1$ no show $)$ \\
\hline Bio-engineering & 4 & 4 & 50.17 (4 no show) & $20.82 \%(5$ no show $)$ \\
\hline Automation and Electronic Information Engineering & 4 & 5 & 55.95 (3 no show) & $20.71 \%(6$ no show $)$ \\
\hline Science & 2 & 4 & 59.69 (1 no show) & $34.19 \%(1$ no show $)$ \\
\hline Economics and Management & 6 & 5 & 77.95 (4 no show) & $32.76 \%(6$ no show $)$ \\
\hline Humanities & 3 & 3 & 62.5 (1 no show) & $25.77 \%$ (1 no show) \\
\hline Politics + Law & 3 & 3 & 67.75 (1 no show) & $29.61 \%(3$ no show) \\
\hline Total & 43 & 46 & Average: 60.53 & Average: $24.97 \%$ \\
\hline
\end{tabular}

Note: Item 1: the number of classes (level A and level B) in the first and second semester; and Item 2: percentage of students passing CET-4 in the respective college or school, "No show"=be absent from the test, and "no show" students are calculated in the percentage.

Concerning classroom teaching methodologies, the differences are obvious for the two levels of classes. Level A students are trained to take College English Test Band Four (CET-4) in middle December 2015. Thus from September to December, teachers employ the "sea" tactics, which involves tremendous amount of exercises both in class and outside class. Students follow the materials of old exams, doing mountains of exercises and teachers will explain in class. Every class is the same: training listening, doing reading comprehension, and composing essays or practicing translation. What a relief. Students' honest efforts have yielded satisfactory results for half of students at least, and over two-thirds (77.9\%) for School of Economics and Management. Level B classes use unitary textbooks in classroom teaching in order to strengthen their basic knowledge.

In the second semester, things become worsening mostly in two aspects as follows. Firstly, level A students feel lost and unfulfilled. In level A 60.94\% pass College English Test Band Four (CET-4) in December 2016, achieving their first success in college English study and getting ready to move on to the second goal of English learning, i.e. preparing for CET-6 in the second semester. But teachers don't train them in class because in class less than half or one-third students who fail to pass CET-4. Some teachers may show more sympathy for this part of students, and add training materials to classroom teaching, and some teachers may treat the two parts of students equally and stick to textbooks teaching in class. In this case two worlds of students lose interest and enthusiasm in English learning. As a result most of them fail to fulfill their goals after the second semester ends. The second point goes to level B students. Level B classes are not allowed to take CET-4 in the first semester. Even so, majority of students feel confident and hopeful with teachers' positive encouragement. They are motivated because they are conscious that what's done this semester is to reinforce their basic knowledge and get prepared for CET-4 in the second semester. But the truth is harsh. Altogether in level B there are 2,180 students, and 1,565 students are picked out to take CET-4 in June 2016, according to their scores of final exam papers (Final exam score $=30 \%$ class performance $+70 \%$ test papers). Obviously classroom environment is filled with complacency and disappointment with "lucky" and "unlucky" in one class. For good of students" test preparation, most teachers adopt tough exercise training in class. Ideally students who win the chance to take the test stay close to teachers and work very hard all the time. But in fact it is not the case. More than half of students give up very soon because of tough boring training over and over again, whereas, those students who don't have the chance to take CET-4, may become deserted, resentful, cynical, or frustrated. Here it is also necessary to bring up the subject of the results of CET-4 shown in Table 1 above. In this semester only College of Science and School of Economics and Management reach over one third of students who pass CET-4, and two other schools (Humanities, Politics + Law) are above the average percentage.

\section{B. Further Improvement in Grade 2016}

To change this situation to better, further improvement has been made in Grade 2016. The first semester is very 
similar to that in Grade 2015. In this academic year, there is one striking feature worth mentioning. First, the once-known Materials and Chemical Engineering is divided into College of Materials and College of Chemical and Environmental Engineering. To save some resources, the two colleges are put together in the grading model. Plus, to coordinate the steps key discipline construction in our university, two key majors are established respectively: one key major of Polymer Material, Brewage and Accounting, the other being key major of Technology, Process Control, and Electric Automation. After taking a grading test in the first week of entering college, freshmen are set in level A and level B. Teaching strategies are adopted similarly as what's done in 2015 Grade. As is expected, the results of CET-4 are quite satisfactory and encouraging, which means our hard work is paid off. However, if taken a close look at the data shown in table 2 below, two points are quite conspicuous. Point 1, Key majors don't perform to their fullest potential as they are accepted in accordance to the standard of provincial key university in College Entrance Examination. Point 2, science students can also be successful in language learning, which is highlighted by School of Chemical Engineering and School of Science. Let's hope it is not lucky coincidence. To be better-directed in classroom teaching, students are further graded as level A, level B and level C in the second semester (See Table 2).

TABLE 2:

CLASS DISTRIBUTIONS OF GRADE 2016

\begin{tabular}{|c|c|c|c|c|c|c|}
\hline \multirow{3}{*}{ Colleges \&.Schools } & \multicolumn{3}{|c|}{$\mathbf{1}^{\text {st }}$ Semester } & \multicolumn{3}{|c|}{$2^{\text {nd }}$ Semester } \\
\hline & \multicolumn{2}{|c|}{ Item 1} & \multirow{2}{*}{ Item 2} & \multirow{2}{*}{$\begin{array}{l}\text { Item } 3 \\
\mathbf{A}\end{array}$} & \multirow{2}{*}{$\begin{array}{l}\text { Item } 4 \\
\text { B } \\
\end{array}$} & \multirow{2}{*}{$\begin{array}{l}\text { Item 5 } \\
\text { C } \\
\end{array}$} \\
\hline & $\mathbf{A}$ & B & & & & \\
\hline $\begin{array}{l}\text { Materials (Major of Polymer Material excluded) }+ \\
\text { Chemical and Environmental Engineering (Major of } \\
\text { Technology excluded) }\end{array}$ & 3 & 4 & $\begin{array}{l}53.59 \\
(1 \text { no show })\end{array}$ & 2 & 3 & 2 \\
\hline Chemical Engineering & 3 & 3 & $\begin{array}{l}64.04 \\
(1 \text { no show })\end{array}$ & 1 & 3 & 2 \\
\hline $\begin{array}{l}\text { Mechanical Engineering } \\
\text { (Major of Process Control excluded) }\end{array}$ & 3 & 6 & $\begin{array}{l}50 \\
(2 \text { no show })\end{array}$ & 1 & 5 & 2 \\
\hline Computer Science & 4 & 5 & $\begin{array}{l}50.68 \\
\text { (2 no show) }\end{array}$ & 2 & 5 & 2 \\
\hline Civil Engineering & 3 & 2 & 60.73 & 2 & 2 & 1 \\
\hline Bio-engineering (Major of Brewage excluded) & 3 & 5 & 62.62 & 2 & 4 & 2 \\
\hline $\begin{array}{l}\text { Automation and Electronic Information } \\
\text { Engineering (Major of Electric Automation } \\
\text { excluded) }\end{array}$ & 3 & 6 & $\begin{array}{l}58.15 \\
(1 \text { no show) }\end{array}$ & 2 & 4 & 3 \\
\hline Science & 2 & 4 & $\begin{array}{l}65.93 \\
(1 \text { no show })\end{array}$ & 1 & 3 & 2 \\
\hline Economics & 3 & 2 & 71.98 & 2 & 2 & 1 \\
\hline Management (Major of Accounting excluded) & 3 & 3 & $\begin{array}{l}80.66 \\
(2 \text { no show) }\end{array}$ & 2 & 3 & 1 \\
\hline Humanities & 4 & 2 & 63.67 & 3 & 2 & 1 \\
\hline Politics + Law & 3 & 3 & 60.64 & 2 & 3 & 1 \\
\hline $\begin{array}{l}\text { Keys majors of Technology + Process Control + } \\
\text { Electric Automation }\end{array}$ & 3 & 2 & 68.02 & 2 & 2 & 1 \\
\hline $\begin{array}{l}\text { Keys majors of Polymer Material + Brewage }+ \\
\text { Accounting }\end{array}$ & 4 & 2 & $\begin{array}{l}73.85 \\
\text { (1 no show) }\end{array}$ & 3 & 3 & 0 \\
\hline Total & 44 & 49 & Average: 63.18 & 27 & 44 & 21 \\
\hline
\end{tabular}

Note: Item 1: the number of classes (level A and level B) in the first semester; Item 2: percentage of students passing CET-4 in the respective college or school," "No show"=be absent from the test; and Item 3, "'no show" students are calculated in the percentage); Item 4 and Item 5: the number of classes (level A, level B and level C) in the second semester.

Level A are students who success in passing CET-4, level B students are taking CET-4 in June 2016, and level C are students who are not allowed to take CET-4 because of their lower scores in final exam papers of first semester. Specifically there are two sub-bands in level B. Level B1 is made up of students who belong to level A in the first semester but fail to pass CET-4 in December 2016, while level B2 are students who are in level B in the first semester and are selected to take CET-4 this semester. Plus there is one point in common worth mentioning: some students choose to be absent from CET-4, while some are eager to have a try but are not qualified. Very soon after the day of CET-4, "no show" students will be questioned routinely by their teachers "why?" The usual answer may be that "they are not quite confident", "they are not yet ready", or something like that. The trust might be "no show" students are not that bad and very likely to pass CET-4 successfully for rare cases. What a pity. They just don't give themselves chances to try. In this case, educational institutions may think about devising some punishment regulations for those irresponsible students. Admittedly pointing out shortcomings doesn't mean to reject this active exploration completely or negates its advantages in advancing college English reformation, but is intended to devise next course of direction.

Here comes a question: what can teachers do to improve the efficiency of classroom teaching? How can teachers satisfy different levels of students for the good of their English study? Obviously for level A, students don't have too much burden to prepare College English Test Band Six as they know CET-6 is much harder than CET-6 and it takes time and patience. What they are most concerned about is to train their practical capacity in the English language use. With teachers' proper direction and students' self-reflection, majority of level B students are confident of keeping up working hard and trying the second time in June 2017. Thus what they care about most in class is to put most trust 
possible on classroom instruction and their abundant exercises after class. Last but not the least, level $\mathrm{C}$ students are most fragile. If taught something difficult, they might give up easily; whereas, if taught in a simple way, they might not be challenged to their potentials, which does no good for their higher stage of English learning.

\section{ANALYSIS}

China College English is a regular but challenging mission, so is classroom teaching for frontline teachers. Its further reformation requires people engaging in teaching (or education) profession to possess teachers' ethics and morals, and most important of all, practice the spirits of commitment, dedication, exploration and innovation on the jobs. Although the grading teaching model is a rewarding exploration in China college English reformation, there are some problems worth mentioning in the expectation that educational institutions are responding promptly so as to make necessary changes as soon as possible.

\section{A. Overburdened Faculty Members}

Yesterday when preparing for lessons for level B classes, I was very much touched by a passage in Depth Reading of Reading Comprehension in old CET-4 test papers. It tells “... Class attendance, educational success, student happiness and well-being might be improved by cutting down the bureaucratic mechanisms and meetings, and instead hiring an army of good teachers. It is bearable to attend some regular meetings which usually are not constructive with ordinary teachers sitting listening no more than half an hour. The faculty meeting is more like some notices repeated and emphasized face to face. The passage continues, "Teachers are not people who are great at and consumed by research and happen to appear in a classroom." The requirement of research is what causes faculty members a continuous headache: all teachers are required to do researches, which accounts for quite a percentage in evaluating whether he or she is an excellent one in annual assessment, e.g. How many articles are published in state core journals? How much is invested or produced in a research project? By this standard efforts and achievements in classroom teaching play a role of a relatively minimal reference. Also as is mentioned in the passage above, "Good teaching and research are not exclusive, but they are not automatic companions." Furthermore, Andrew Johnson (2015) illustrates via linkedin shares, teaching is "science in that there are strategies and practices that a body of research has shown to be effective in enhancing learning.", "an art in that teachers must bring themselves fully into their teaching and is "a craft is a skill or set of skills learned through experience." Moreover, a third point is thought-provoking too. Both teachers and students are suffered from very large sizes of classes. From Table 3, we can see in Grade 2015, the number of students are normally assigned in classes A or B ranging from 60 to 69. But in Grade 2016, in the first semester there are numbers of classes with students' number ranging from 70 and 79 , and exceeding 80 in one class; what's worse, in the second semester all levels of classes expand. Among the number of students above 70, there are seven level A classes, eight level B classes and twelve level C classes. In such huge numbers of classes, it is really not an easy cake to organize effective class activities each time. Convincing reasons to explain large classes can be shortages of increased enrollments year by year and lacks of qualified good teachers. In Grade 2015 twenty-five English teachers undertake the task of English course for non-English majors freshmen. In the first semester of Grade 2016 there are twenty-nine teachers and in the second semester there are thirty-one teachers for freshmen' teaching task.

TABLE 3:

THE NUMBER OF CLASSES

\begin{tabular}{|c|c|c|c|c|c|c|c|}
\hline \multirow{3}{*}{ Items } & \multirow{2}{*}{\multicolumn{2}{|c|}{$\begin{array}{l}\text { Grade } 2015 \\
1^{\text {st }}+2^{\text {nd }} \text { Semesters }\end{array}$}} & \multicolumn{5}{|c|}{ Grade 2016} \\
\hline & & & \multicolumn{2}{|c|}{$1^{\text {st }}$ Semester } & \multicolumn{3}{|c|}{$2^{\text {nd }}$ Semester } \\
\hline & $\mathrm{A}$ & $\mathrm{B}$ & $\mathrm{A}$ & $\mathrm{B}$ & $\mathrm{A}$ & $\mathrm{B}$ & $\mathrm{C}$ \\
\hline $99 \sim 90$ & & & & & 1 & 1 & 1 \\
\hline $89 \sim 80$ & & & & 1 & 2 & 1 & 4 \\
\hline $79 \sim 70$ & & 7 & 6 & 3 & 4 & 6 & 7 \\
\hline $69 \sim 60$ & 43 & 34 & 38 & 45 & 10 & 18 & 5 \\
\hline $59 \sim 50$ & & 5 & & & 10 & 15 & 2 \\
\hline $49 \sim 40$ & & & & & & 3 & 2 \\
\hline
\end{tabular}

Note: Items, the number of students in one English class. Column "A", "B", or "C" shows the number of classes in certain number of students in one class.

Anyone with common sense in foreign language learning can understand this kind of classroom teaching involves numerous in-class practice which requires teachers' individual instruction in most cases. Specifically teachers are supposed to correct students pronunciation, read their compositions, test their listening skills in listening and speaking; knowing every student' processes of learning activities and their increment of knowledge and skills. All in all, students, parents, universities and society ideally expect teachers to take full responsibility. But in such larger classes, what's the best of doing this? One more point may account for something. Currently in our university administrative staff noticeably outnumber classroom teachers in proportion to the amount of workload. As is stated in the reading passage above, "If we replaced half of our administrative staff with classroom teachers, we might actually get a majority of our classes back to 20 or fewer students per teacher." In such a case, better qualities of teachers are in most need. Why are there so many students in one class? One more truth will be revealed in the following. 


\section{B. Lack of Necessary Language Teaching Equipment}

In freshmen campus of our university (40mins' commuting bus journey from main university in city) there are four language labs for 4,946 undergraduates of freshmen year in Grade 2015 and 5,976 (undergraduates of freshmen year) in Grade 2016. Obviously it is not realistic to schedule all classes in such laboratories. The second option is to use networked-computer classrooms (multimedia), however, less than half of classrooms are multimedia which satisfy the needs of all courses like computer science for non-computer majors, English for non-English majors, maths for non-maths majors, and just to name a few. The eclectic strategy is to schedule one time of English classes to the multimedia classroom every week. In our university each class period lasts 45 minutes. Usually there are two class periods each time for every course. As to English course, non-English undergraduates have four class periods (two times of 2/45-mins) every week. To remedy the shortage of classroom resources, both teachers and students have tight schedules of classes. What's more, larger sizes of classes do the trick.

Teachers are very adaptive, too. When teaching activities are conducted in traditional classrooms where textbooks, chalk and blackboard are available, teachers talk a lot as hard-working students are much dependent of taking abundant notes and feel fulfilled after class. As we know, teachers' knowledge is far too limited especially in the ages of information technologies. Tremendous amount of resources are just within one click's away. When in multimedia classrooms teachers play relevant video clips of world people, cultures, customs, festivals, music and movies, and show show learning strategies in foreign language, college life or study around the globe while students watch, listen, laugh or talk. English classes can be very interesting and beneficial. Also the Requirements (2007) recommend, "In view of the marked increase in student enrollments and the relatively limited resources, colleges and universities should remould the existing unitary teacher-centered pattern of language teaching by introducing computer- and classroom-based teaching models."

\section{Relation to High School Teaching Styles}

Weeks ago on our school commuting bus I happened to sit next to a teacher of Japanese who I had been thinking about talking to him for some time. Though we are colleagues in School of Foreign Languages in our university, we have few chances to meet in person. I asked him a long-prepared question, "How can Japanese majors study well enough to seek employment after four years of university study since they haven't learned Japanese before college? You know, we English teachers feel a headache that non-English majors' English seems to stay at the same level though they have learned at least six years before college and college teachers are trying all means to help." "Just think and reexamine styles in teaching and learning. How do high school teachers teach English? For what do high school students study hard at English? You can also think about how you learned English back in high school? And upon entering college as English major, how did you train yours skills in English?" After those questions, the Japanese teacher explained how teaches Japanese majors. The talk illuminates me! Before college, junior and senior high school schools are pouring a wealth of time, energy and attention to this "most important" required course in entrance exams to next stage of education. For this topic, in my article entitled "Rethinking the Way out for College English Teaching ---After China's Reform in National College Entrance Exam in English" published in 2014, I talk about some in relation to "gaokao" reform in College Entrance Examination in English course. To increase students' scores in corresponding exams (e.g. Senior High Entrance Examination, CEE), teachers' usual practice is to adopt "sea" tactics: design numerous exercises in knowledge of vocabulary, grammar, reading passages, and essay-writing, which are largely based on researches of old entrance exams. From this point we can see teachers are like a strategist besides being a scientist, artist and craftsman/woman. Few teachers are concerned about students' development of comprehensive skills especially in practical use. Fortunately both in SHEE and CEE, listening comprehension is included in the test exercises. Teachers are paying some attention to it. In this way speaking skills are suggested being included in all levels of entrance examinations. Fairly speaking, under the pressure of examination-oriented education system, teachers are not the only party to be blamed or even shoulder the responsibility.

Starting from junior high school, students depend heavily on teachers' inculcation of knowledge and thus, become silent learners and responsible note-takers. Under this circumstance, neither educators nor the educated take time to conduct emotional communication and hearty exchanges. The most forceful standard is by scores in entrance examinations. Over time students have developed some old habits difficult to change when at college where they are liberated from stressful entrance exams and are encouraged to develop their personal interests in such relatively relaxing learning environment. Responsible college English teachers are conscious of the importance of strengthening students' communicative competency and increasing their cultural awareness and literacy for the benefits of their future career. Though time and chances are given for students to participate, few students (even some "brilliant" students in English course) participate in class discussion. Normally students who are willing to stand up and take part in class activities are "average-level", which sometimes put teachers in a dilemma because teachers promise to reward "active" students with extra scores in final exam but their class contributions are not good enough to be rewarded except for their courage in "speaking” English, whereas, "brilliant" students don't care about extra awards because they can achieve good grades in test papers. Seriously speaking, a tough mission presents in front of classroom teachers. As a strategist to help students to cope with numerous tests or exams in their learning career, college English teachers are expected to design some efficient strategies to arouse students' enthusiasm, stimulate their motivation and facilitate their efficacy in classroom 
teaching.

\section{CONCLUSION}

From what's discussed above, we can conclude as follows. To start with we are implementing the grading model for the good of avoiding disadvantages of traditional mod based on natural classed. When the new model is underway, we realize it is not thin enough to place students according to their specific majors of different colleges or schools because of numerous intangible things involved and lack of teaching resources like teachers and computer-based classrooms. On the conditions of the present grading model and its existing resources, college teachers are confronted with a tough task to devise some effective methods for the benefits of college English learners.

College English education is a long-term task of exploration, experiment and reformation. As an old Chinese proverb from "Springs and Autumns of Master Lü” goes, "Running water doesn't stink and a moving hinge doesn't stick"(or literally "Running is never stale and a door-hinge never gets worm-eaten." or a rolling stone gathers no moss.). "Currently the grading model has become a popular mainstream in college English teaching"(Haixiao Wang, 2009). Still there are some worth our attention and reflection. For one thing, we frontline teachers should be more forward-looking and innovative in using individual talents to teach and achieve the goals of the course. For another, educational institutions should make timely changes of concepts, creating favorable conditions possible for actual classroom teaching, such as increasing more computer-based classrooms and hiring more highly-skilled classroom teachers. For the third, English testing systems at all levels are in need of necessary modifications so that classroom teaching can be improved correspondingly. Whatever is done, it is for the good of an overall quality of higher education. Last but not the least, the grading model seems not to be an ideal one, it is needed to keep on experimenting till a better one is found.

\section{REFERENCES}

[1] Andrew Johnson, Ph.D. (2015). The Science, Art and Craft of Teaching. http://www.linkedin.com/pulse/teaching-science-art-craft-andrew-johnson. (accessed 22/03/2017).

[2] Higher Education Commission of. (2007). College English Curriculum Requirements, Shanghai: Shanghai Foreign Language Education Press.

[3] Liu Peng. (2014). Rethinking the Way out for College English Teaching ---After China's Reform in National College Entrance Exam in English. Theory and Practice in Language Studies, 4, 110-115.

[4] Ministry of China Education. (2016). College English Test Band Four. Shanghai: CET-4/6 Proposition Group of Shanghai Jiaotong University.

[5] Haixiao Wang. (2009). Questionnaire Survey of College English Teachers and Teaching. Foreign Language World, 4, 6-13.

Liu Peng, was born in Chongqing, China in 1976. She received M.A. degree in applied linguistics from University of Electronic Science and Technology of Chengdu, China in 2012.

She is currently an English lecturer in School of Foreign Languages, Sichuan University of Science and Engineering, Zigong, China. Her research focuses on EFL teaching.

Chunrong Wu, was born in Yinbin, China in 1973. In June 2000 she graduated from Southwest University with M.A. Degree in applied linguistics. From Apr. 2014 to Dec. 2016 her research on "A Pragmatic-translation approach to research on applied translation" is financed by by Research Project of Education Department of Sichuan Province.

She is currently a professor of the English language in School of Foreign Languages, Sichuan University of Science and Engineering, Zigong, China. Her research specialization is in applied linguistics and translation.

Xianjun Tan, was born in Zigong, China in 1982. In June 20011 he graduated from University of Electronic Science and Technology of China (Chengdu, China) with M.A. Degree in Foreign Linguistics and Applied Linguistics. From Jan. 2014 to Dec. 2015, his research on "Current situations and correspondent strategies of Cultural Zigong" is financed by Research Project of Education Department of Sichuan Province.

$\mathrm{He}$ is currently the chief of administrative office in International Cooperation and Exchanges Office in Sichuan University of Science and Engineering, Zigong, China. His research focuses on applied linguistics, foreign language teaching, Chinese culture and foreign cultures. 